
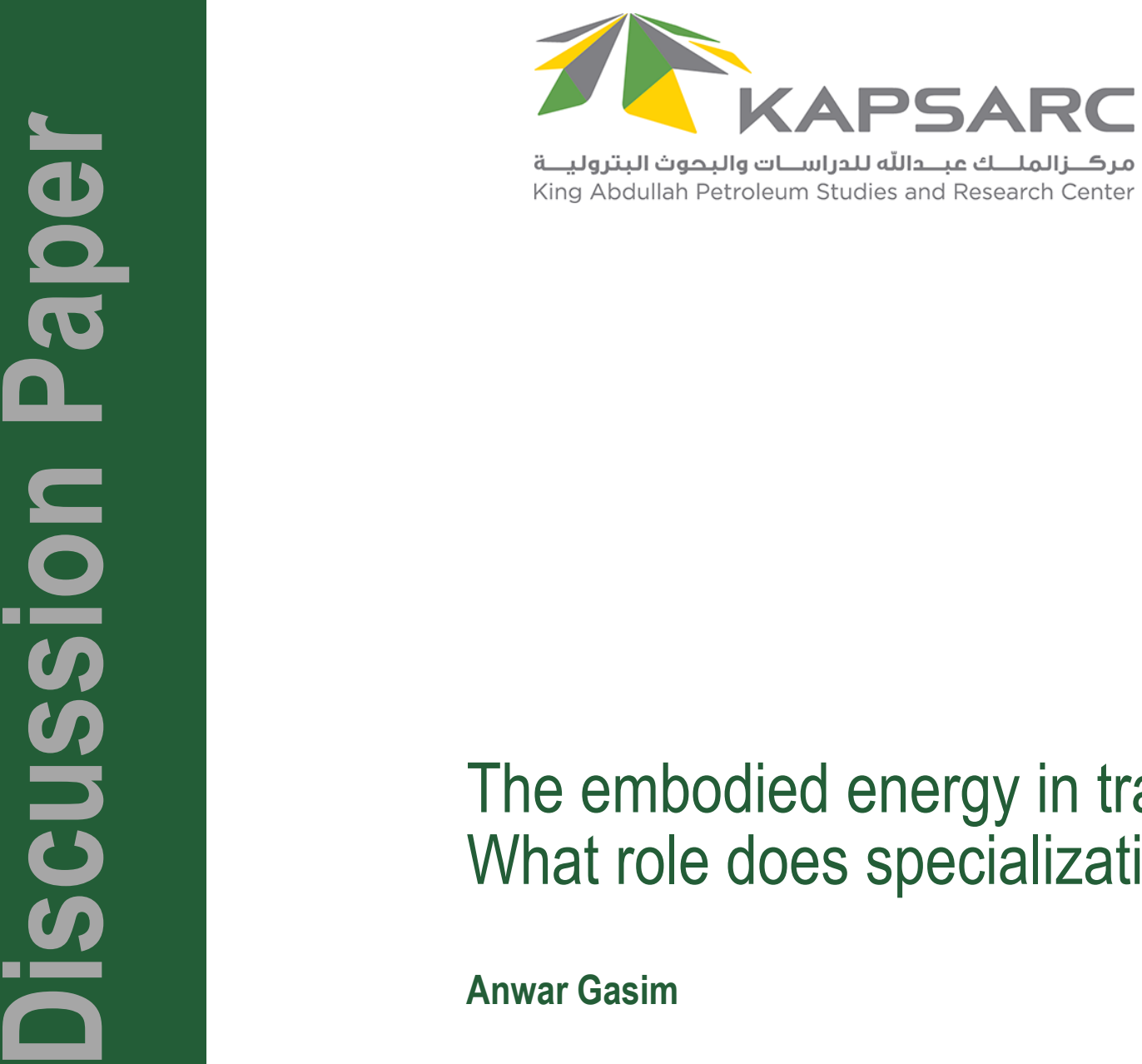

\title{
The embodied energy in trade: What role does specialization play?
}

\author{
Anwar Gasim
}




\section{About KAPSARC}

The King Abdullah Petroleum Studies and Research Center (KAPSARC) is an independent, non-profit research institution dedicated to researching energy economics, policy, technology, and the environment across all types of energy. KAPSARC's mandate is to advance the understanding of energy challenges and opportunities facing the world today and tomorrow, through unbiased, independent, and high-caliber research for the benefit of society. KAPSARC is located in Riyadh, Saudi Arabia.

\section{Legal notice}

(C) Copyright 2015 King Abdullah Petroleum Studies and Research Center (KAPSARC). No portion of this document may be reproduced or utilized without the proper attribution to KAPSARC. 


\section{Summary}

In global discussions aimed at limiting greenhouse gas emissions, the national targets set by governments are tied to the energy used or emissions generated within national borders. However, international trade can confuse the accounting. Moving a factory across the border does not change the total emissions, only the country to which they are attributed. Because of this, there is a growing consensus that the embodied emissions in international trade may undermine efforts to mitigate climate change.

This has led to a number of studies that investigate the embodied emissions in international trade. Their findings have consistently demonstrated that industrialized countries tend to be net importers of embodied energy and emissions, while developing countries tend to be net exporters. It is often assumed that the industrialized countries have "offshored" energy intensive industries to developing countries, which in turn have specialized in energy intensive production.

Some countries have started to adopt national targets around energy productivity, an indicator that links energy use to gross domestic product. Energy productivity has recently gained increased interest because it accommodates economic growth, is conceptually tied to energy efficiency - seen by policymakers as a low cost solution to limiting emissions - and focuses attention on how to maximize the welfare extracted from the energy system.

We examine the issue of offshoring and specialization through the lens of embodied energy. First, we calculate the embodied energy in the net exports of 41 economies. We then decompose the embodied energy in net exports for each economy into three effects - intensity, specialization, and the trade balance - to reveal why each economy is a net exporter or importer of embodied energy. Each effect is described below:

- The intensity effect loosely reflects how differences in energy efficiency influence the embodied energy in a country's net exports. For example, consider two countries that engage in the trade of steel. Suppose each country is exporting the same volume of steel to the other. One of the countries would be a net exporter of embodied energy if it was less efficient in production, as its steel exports would embody more energy than its steel imports.

- The specialization effect captures how differences in the mix of goods and services that are traded influence the embodied energy in net exports. For example, if Saudi Arabia is exporting petrochemicals to the USA and importing various food products, then Saudi Arabia would be a net exporter of embodied energy due to its much more energy intensive exports.

- The trade balance effect reflects how differences in the volume of exports and imports influence the embodied energy in net exports. Returning to the steel example and allowing both countries to be equally efficient at producing steel, if one country exports ten tonnes of steel and imports five tonnes from the other country, the former will be a net exporter of embodied energy because of that trade surplus.

Our decomposition results reveal that specialization, on average, makes the biggest contribution to a country's embodied energy in net exports. By looking at the direction of the specialization effect, it is found that many industrialized countries have offshored energy intensive industries, while many 
developing countries are specialized in energy intensive exports. Despite the importance of the specialization effect, the combination of the intensity and trade balance effects is equally important in shaping a country's embodied energy in net exports. Offshoring, despite its significant role, is not the only cause of the embodied energy trade patterns observed between industrialized and developing countries.

Why does any of this matter? Shifts in economic structure can occur in both directions. Over the last few decades, many manufacturing industries have moved from the USA to developing countries such as China and Saudi Arabia, where labour and energy costs have been lower. This is the well-known offshoring narrative. More recently, manufacturing in the USA has been undergoing a renaissance, giving rise to the term "reshoring". The reshoring of manufacturing is believed to be driven by China's rising labour costs. Furthermore, in the case of energy intensive manufacturing, its reshoring has largely been instigated by the cheap natural gas that has been unlocked in the US through the shale boom.

The reshoring of energy intensive industries may make it harder to achieve the US target of doubling energy productivity by 2030 . However, accounting for the impact of the embodied energy in international trade, and in particular, the contributions of offshoring and specialization, provides policymakers with key insights into the consequences of such shifts in economic structure.

\section{Introduction to offshoring and the embodied energy in trade}

International trade, measured as a percentage of world gross domestic product, has grown from roughly $25 \%$ in 1960 to $60 \%$ in 2012 , according to the World Bank. This has led to increased concerns over the link between energy use, greenhouse gas emissions, and trade, which have prompted a number of studies to investigate the embodied energy and emissions in international trade [1-4].

The term "embodied energy" refers to the total energy that was consumed directly and indirectly along the entire production chain of a good or service. Analogously, the embodied emissions are the total emissions that were emitted along the entire production chain. For instance, the embodied energy in a car encompasses the energy that was used to assemble all of its parts, the energy that was used in the manufacturing of those parts (which include plastics, steel, and aluminium), and the energy that was used to extract and deliver the raw materials and fossil fuels that were consumed during the various manufacturing processes.

The complexity of supply chains makes it difficult to quantify the embodied energy in a particular good or service. However, input-output tables provide a method for doing so. An input-output table is a matrix of all the monetary flows between industries in an economy. For example, it shows how much electricity was purchased from the power sector by the iron and steel sector to produce its output, and where that output went. Combined with energy consumption data for each industry, the monetary flows in an input-output table can be converted into energy flows, allowing for the calculation of the embodied energy in a good or service. Alongside bilateral trade data, one can calculate the total embodied energy in a country's exports and imports.

If the embodied energy in a country's exports is greater than the embodied energy in its imports, then the country is a net exporter of embodied energy. On the other hand, if the embodied energy in a country's exports is less than the embodied energy in its imports, then the country is a net importer of embodied energy. 
Using input-output tables, it has been demonstrated that industrialized countries are net importers of embodied energy and emissions, while developing countries are net exporters [5]. Notably, Peters found that the increase in embodied emissions imported by industrialized countries was larger than their Kyoto Protocol emission reductions over the same period [6]. It has been suggested that the "offshoring" or "outsourcing" of energy intensive industries to developing countries has been driving these trade patterns.

Offshoring in this context describes the shift of energy intensive industries from one country to another. While a small part of offshoring may be caused by differences in energy and carbon policy between countries, most of it has been caused by shifts in comparative advantage. In general, countries will specialize in production that requires factors that they possess in abundance. For example, countries that are relatively more abundant in low cost fossil fuels or cheap hydro power are likely to specialize in energy intensive exports. In Saudi Arabia for instance, the low ethane price has propelled it to be one of the world's leading exporters of petrochemicals.

It is well known how much countries can gain by specializing in their areas of comparative advantage and engaging in trade. The economic benefits of offshoring as a result of shifts in comparative advantage have been huge. For developing countries, the benefits include a greater number of jobs and a rising standard of living. For industrialized countries, prices of goods have fallen and consumers have gained access to more goods and services.

Offshoring does have some disadvantages though. An energy intensive industry may move from an energy efficient country to a less efficient country, potentially resulting in increased global emissions.
This is known as carbon leakage. Nevertheless, the benefits of offshoring are expected to be far larger than the costs.

Offshoring and specialization are two sides of the same coin. If Saudi Arabia is exporting petrochemicals to the US and importing various food products, then Saudi Arabia is deemed to be specialized in energy intensive exports while the US is regarded to have offshored energy intensive production. To emphasize, our use of the terms offshoring and specialization is with respect to energy intensive production. A country may specialize in labour-intensive exports for instance, but our use of the terms "offshoring" and "specialization" in this paper is strictly from an energy perspective.

Concluding that the embodied energy and emissions trade patterns are a result of offshoring appears commonsense. Manufacturing firms in the world's industrialized countries have indeed offshored many of their activities to developing countries. However, can we completely attribute these trade patterns between industrialized and developing countries to offshoring and specialization?

The assumption that developing countries - which are net exporters of embodied energy-are specialized in energy intensive exports, and industrialized countries - which are net importers of embodied energy - have offshored energy intensive industries, is not always true. There are other factors that can cause a country to be a net exporter or importer of embodied energy. For instance, consider a country, Exportistan, trading with the rest of the world. Suppose both economies have identical levels of energy efficiency and neither is specialized. Because of Exportistan's trade surplus with the rest of the world, it will be a net exporter of embodied energy by virtue of its surplus, despite not 
being specialized in energy intensive exports. Likewise, consider a second country, Frugalia, trading with the rest of the world. Suppose neither is specialized and that their trade is balanced. Frugalia would be a net importer of embodied energy if it was more energy efficient than the rest of the world, as its exports would carry less embodied energy than its imports, with offshoring playing no role. The factors that can influence the embodied energy in a country's net exports are:

- Differences in efficiency: The difference between the efficiency with which energy is used to produce exports and the efficiency with which energy is used to produce imports. The less efficient a country is relative to its trade partners, the greater the energy embodied in its net exports.

- Differences in specialization: The difference between the mix of goods and services that is exported and the mix that is imported. This is what many articles have assumed to be the cause of the observed embodied emissions trade patterns. The more energy intensive the mix of goods and services that is exported relative to what is imported, the greater the energy embodied in net exports.

- Trade balance: The difference between the volume of exports and the volume of imports. Clearly, the greater the volume of goods that is exported relative to what is imported, the greater the energy embodied in net exports.

Building on the pioneering work of Edward Leamer, Michael Jakob, and Robert Marschinski [7, 8], we use the World Input-Output Database, a large multicountry input-output table [9], to investigate how these factors contribute to the embodied energy in the net exports of 41 economies.

\section{The contributors to the embodied energy in trade}

There are two models for calculating the embodied energy in trade [10]. To understand the difference between the two, consider an example where Japan exports steel to China, which is entirely consumed by Chinese industries to produce manufactured goods for export to the US. The embodied energy in bilateral trade (EEBT) model would attribute the embodied energy in the Japanese steel to China, since China is the nation that directly imports the steel. In contrast, the multi-regional input-output (MRIO) model would attribute the embodied energy in the Japanese steel to the US, since it is indirectly imported by the US as part of the manufactured goods. In other words, the EEBT model attributes the embodied energy in a traded good to the first point of consumption, while the MRIO model attributes it to the final point of consumption (see Figure 1). In the case of the electronic products in Figure 1, the first point is also the final point, so both models attribute the embodied energy in the Japanese electronic products to China.

Our calculations of the embodied energy in the net exports of 40 countries and an aggregation of all the remaining countries into a single region labelled the Rest of World (ROW), are shown in Figure 2. The embodied energy values are expressed in million tonnes of oil equivalent (Mtoe). Furthermore, the countries are labelled using the United Nations ISO codes.

For most countries, calculations of the embodied energy in net exports do not differ substantially between the two models. However, for a few countries the difference was large. In South Korea for example, its export-oriented industries rely heavily on imports to produce their exports. Under the EEBT model, those imports were attributed to 


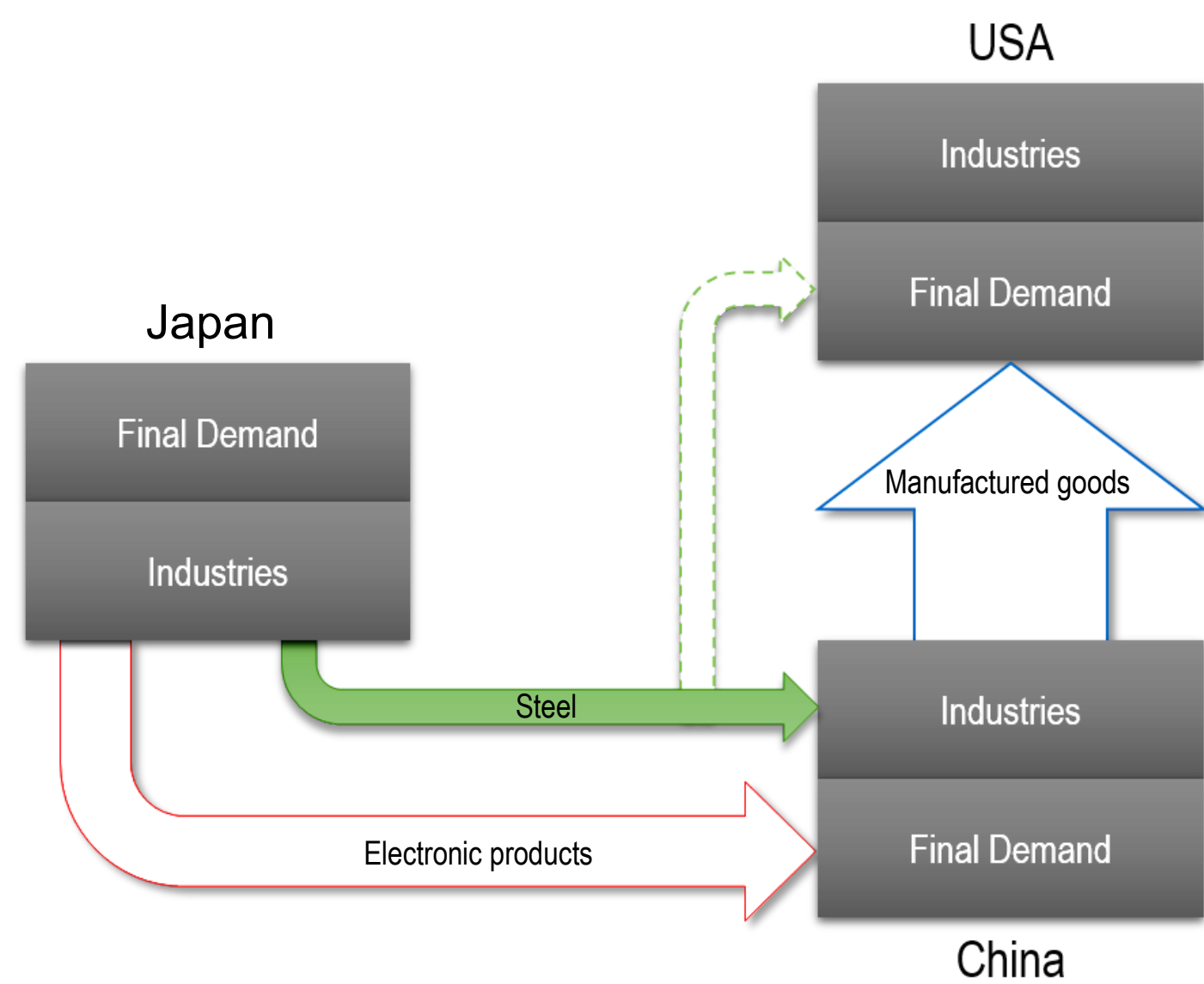

Figure 1: The difference between the EEBT and MRIO models. Arrows represent embodied energy flows. Under the EEBT model, the embodied energy in the steel is attributed to China (solid green line). Under the MRIO model, it is attributed to the USA (dashed green line).

South Korea. Under the MRIO model, the imports were attributed to the country that consumed the final goods that were exported by the South Korean industries. Because the MRIO model better captures the complexity of global supply chains, it is used for the analysis in this paper.

The results in Figure 2 confirm that industrialized countries are net importers of embodied energy and developing countries net exporters. While some developing countries, such as India, presented small net exports of embodied energy, their bilateral embodied energy flows to industrialized countries were often larger (see Figure 3). For example, India, which had a net embodied energy surplus of only 1
Mtoe, had net exports of 14 Mtoe to the US but net imports from China of 12 Mtoe.

To understand which factors are giving rise to this distinction between industrialized and developing economies, we conduct a decomposition analysis on each economy's embodied energy in net exports.

Decomposition analysis is a mathematical tool for calculating the contribution of different factors to an index.

To conduct decomposition analysis, one needs a difference to decompose. The difference that we investigate in this paper is the difference between the 


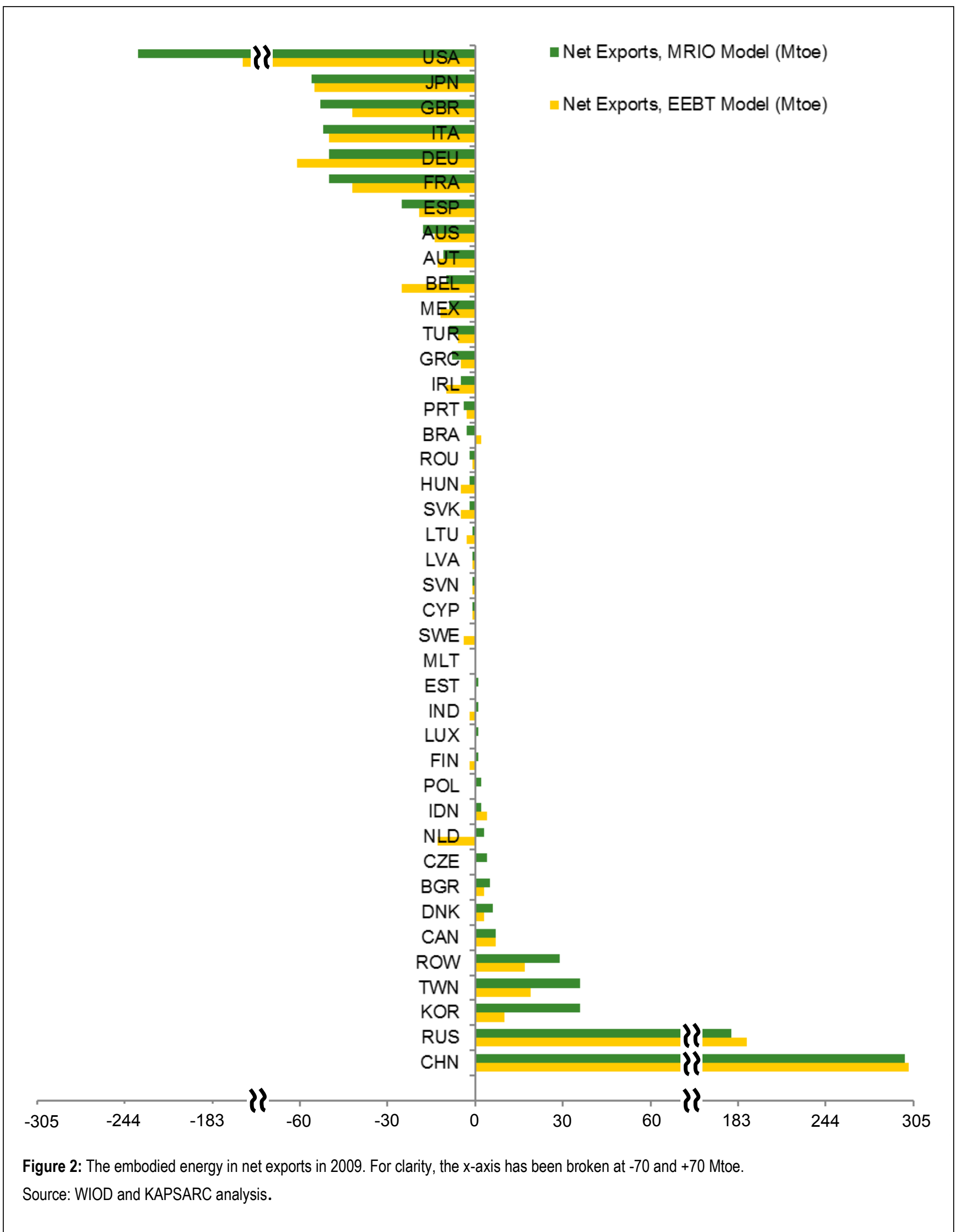




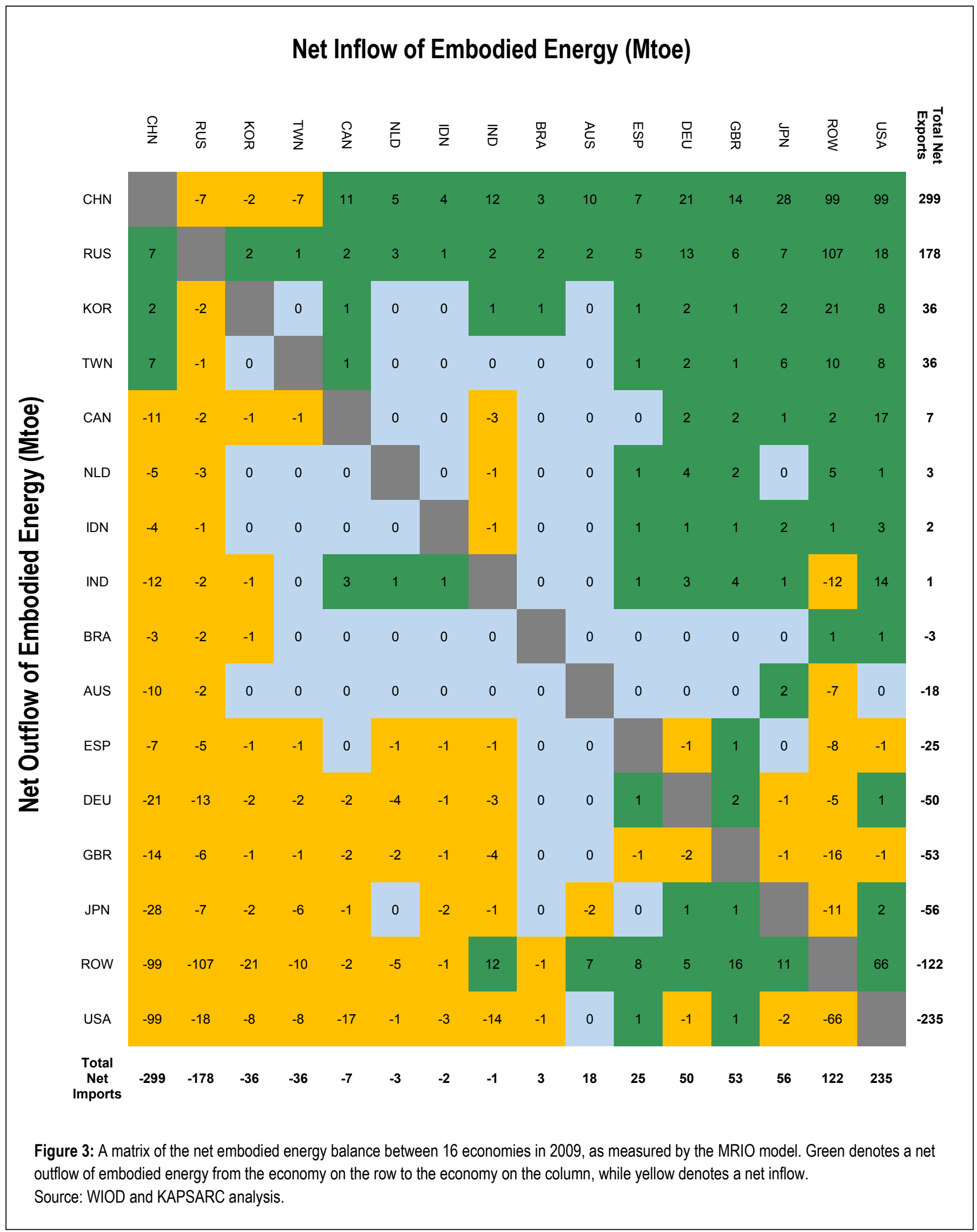


embodied energy in exports and the embodied energy in imports, i.e. the embodied energy in net exports.

We decompose the embodied energy in net exports into three terms: an intensity effect, a specialization effect, and a trade balance effect. The sum of the three effects equals the embodied energy in net exports.

Details on the decomposition methodology can be found in the Appendix. However, an understanding of the three decomposition terms is required to interpret the insights from the analysis:

- The intensity effect: This is used as a proxy for measuring how much energy inefficiency contributes to a country's embodied energy in net exports. A positive intensity effect implies that energy inefficiency is causing a country's exports to embody more energy than its imports, leading to positive net exports of embodied energy. In contrast, a negative intensity effect implies that energy efficiency is causing a country's exports to embody less energy than its imports, leading to negative net exports (i.e. net imports) of embodied energy.

- The specialization effect: This is used to compare how much offshoring and specialization contribute to a country's embodied energy in net exports. A positive specialization effect implies that a country's exports are relatively more energy intensive than its imports, leading to positive net exports of embodied energy. In contrast, a negative specialization effect implies that a country's exports are less energy intensive than its imports, leading to net imports of embodied energy. Thus, a specialization in energy intensive exports yields a positive specialization effect, while the offshoring of energy intensive industries yields a negative specialization effect. Note that the more a country offshores energy intensive industries, the more negative its specialization effect will be and the greater the embodied energy in its net imports.

- The trade balance effect: This reflects how much the difference between the volume of exports and the volume of imports contributes to a country's embodied energy in net exports. In other words, it measures the contribution of the trade balance.

\section{Results and discussion}

The decomposition analysis reveals that, on average, the specialization effect makes the largest contribution to the embodied energy in trade, accounting for roughly $50 \%$. However, despite the importance of the specialization effect, the combination of the intensity and trade balance effects is equally important and cannot be overlooked.

The specialization effect (positive or negative) identifies whether a country is specialized in energy intensive exports or has offshored its energy intensive industries. Our decomposition results confirm that many industrialized countries have indeed offshored energy intensive industries, as measured by their negative specialization effects. In contrast, many developing countries are specialized in energy intensive exports, as measured by their positive specialization effects. In other words, the offshoring narrative is partially correct, since it explains part of the observed embodied energy trends between industrialized and developing countries.

Table 1 presents the full decomposition results for the year 2009. At one end of the spectrum lies China, the largest net exporter of embodied energy. China's net exports were 299 Mtoe, out of which 129 can be attributed to its specialization in energy intensive exports. The intensity effect contributed 95 
Mtoe. This suggests that China's less efficient use of energy has played a role; however, the 95 Mtoe cannot be completely attributed to energy inefficiency since other factors influence the intensity effect (such as energy prices, climate, income, and so on). Finally, China's trade surplus made up the remainder, some 74 Mtoe.

At the other end of the spectrum lies the US, the largest net importer of embodied energy. Net imports for the US registered at 235 Mtoe. The offshoring of energy intensive industries to other countries contributed 156 Mtoe to the USA's net imports of embodied energy. The intensity effect contributed only 10 Mtoe, suggesting that the USA is only slightly more energy efficient than the rest of the world. Finally, the US trade deficit accounted for 68 Mtoe of the embodied energy in net imports.

Many Western/Central European nations, including Austria, Belgium, France, Germany, and Great Britain, were net importers of embodied energy. While the higher levels of energy efficiency in these countries contributed to their positions as net importers - as revealed by their negative intensity effects - offshoring appears to have played a more significant role. The decomposition analysis for these countries generally revealed large negative specialization effects, confirming that these countries have indeed offshored energy intensive industries.

Not all Western/Central European nations have offshored energy intensive industries. For example, The Netherlands registers a small positive specialization effect of 5 Mtoe. This likely stems from its position as the oil-refining center of Europe. Portugal and Spain also appear to enjoy a small positive specialization effect (3 and 4 Mtoe respectively), in contrast to their neighbours. However, such a small value is not necessarily significant considering the uncertainty inherent in these estimates (we estimate the margin of error at \pm 5 Mtoe). Nevertheless, these values are in sharp contrast to the large negative specialization effects exhibited by France (36 Mtoe), Germany (66 Mtoe), and Great Britain (30 Mtoe).

This contrast is likely the result of countries such as France, which had offshored low value added manufacturing to Portugal and Spain in the past due to the lower labour costs in both countries. More recently, many of these industries in Western Europe have been offshored to Central/Eastern European nations-such as Bulgaria, Czech Republic, Poland, and Romania, and to a larger degree, to Asia. Nevertheless, the remaining presence of low value-added manufacturing in Portugal and Spain is likely to be behind this result.

Reiterating, a negative specialization effect is indicative of offshoring. Considering the margin of error, any specialization effect that is more negative than 10 Mtoe is taken to be indicative of offshoring. The results in Table 1 indicate that industrialized nations-such as Australia, Belgium, France, Germany, Great Britain, Italy, Japan, and the US have offshored energy intensive industries. However, in almost all cases, offshoring was not the only reason these countries were net importers of embodied energy. The trade deficits and the higher levels of energy efficiency generally played an equally important role in making these countries net importers of embodied energy.

On the other hand, a positive specialization effect implies specialization in energy intensive exports. Taking 10 Mtoe as the cut-off point for a country to be specialized in energy intensive industries, Russia, India, and China were all found to be specialized. Furthermore, export-oriented countries-such as South Korea and Taiwan-were also strongly specialized. However, in most cases, specialization was not the only cause, as energy inefficiency and 
The embodied energy in trade: What role does specialization play?

\begin{tabular}{|c|c|c|c|c|}
\hline Country & Intensity Effect & $\begin{array}{c}\text { Specialization } \\
\text { Effect }\end{array}$ & $\begin{array}{c}\text { Trade Balance } \\
\text { Effect }\end{array}$ & Net Exports of Embodied Energy \\
\hline CHN & 95 & 129 & 74 & 299 \\
\hline RUS & 39 & 109 & 30 & 178 \\
\hline KOR & 3 & 23 & 10 & 36 \\
\hline TWN & -6 & 35 & 7 & 36 \\
\hline ROW & 49 & 68 & -88 & 29 \\
\hline CAN & 19 & -12 & -1 & 7 \\
\hline DNK & -2 & 6 & 2 & 6 \\
\hline BGR & 0 & 6 & -1 & 5 \\
\hline CZE & 1 & 2 & 1 & 4 \\
\hline NLD & -10 & 5 & 8 & 3 \\
\hline IDN & 4 & -7 & 5 & 2 \\
\hline POL & -4 & 5 & 1 & 2 \\
\hline FIN & 4 & -4 & 1 & 1 \\
\hline LUX & 0 & 1 & 1 & 1 \\
\hline IND & 1 & 13 & -13 & 1 \\
\hline EST & 1 & 0 & 0 & 1 \\
\hline MLT & 0 & 1 & 0 & 0 \\
\hline SWE & 2 & -6 & 4 & 0 \\
\hline CYP & 0 & 0 & -1 & -1 \\
\hline SVN & 0 & -1 & 0 & -1 \\
\hline LVA & 0 & -1 & 0 & -1 \\
\hline LTU & 0 & -2 & 0 & -1 \\
\hline SVK & -1 & -2 & 0 & -2 \\
\hline HUN & -1 & -2 & 1 & -2 \\
\hline ROU & -3 & 2 & -2 & -2 \\
\hline BRA & -11 & 6 & 2 & -3 \\
\hline PRT & -4 & 3 & -3 & -4 \\
\hline IRL & -1 & -7 & 2 & -5 \\
\hline GRC & -4 & 6 & -10 & -8 \\
\hline TUR & -11 & 6 & -4 & -9 \\
\hline MEX & -15 & 6 & 0 & -9 \\
\hline BEL & 1 & -13 & 3 & -10 \\
\hline AUT & -3 & -10 & 2 & -11 \\
\hline AUS & 0 & -20 & 2 & -18 \\
\hline ESP & -21 & 4 & -8 & -25 \\
\hline FRA & -10 & -36 & -4 & -50 \\
\hline DEU & -16 & -66 & 31 & -50 \\
\hline ITA & -22 & -29 & -1 & -52 \\
\hline GBR & -22 & -30 & -1 & -53 \\
\hline JPN & -21 & -48 & 13 & -56 \\
\hline USA & -10 & -156 & -68 & -235 \\
\hline Averages & 10 & 22 & 10 & 30 \\
\hline
\end{tabular}


the trade surpluses in some of these countries contributed to making them net exporters of embodied energy. Finally, the ROW, which combines developing South American, Middle Eastern, and African nations, aggregated to a net specialization effect of 68 Mtoe.

The embodied energy in net exports, along with the three decomposition terms, yield positive or negative values, but with an average of zero. To gain a better understanding of the general size of these terms, we use absolute values. In other words, we consider negative net exports to be positive net imports, thereby eliminating the minus signs and allowing us to compare the relative importance of the three decomposition terms.

Using this approach, the global average of the embodied energy in net exports was calculated to be 30 Mtoe in 2009. Among the three decomposition terms, the specialization effect was revealed to be the most important, averaging 22 Mtoe. However, the intensity and trade balance effects each averaged 10 Mtoe - jointly just as important as specialization. Although the three effects add up to exactly equal the embodied energy in net exports for a single country, this is not the case when looking at the global averages. This is because a country could be a net importer of embodied energy (negative sign) while being specialized in energy intensive exports (positive sign). Such a distinction is lost when absolute values are used.

The values obtained for the averages depend on the countries that are selected. In our study, we include 40 countries and the ROW. Of course, if the ROW was broken down into many smaller countries, then the averages would be lower. However, the absolute size of the averages is not as important as their size relative to one another. Although including more countries in our calculations would yield lower averages, the relative sizes of the three effects would remain largely unchanged. That is, specialization would still retain its position as the most important contributor.

The decomposition analysis was extended to cover all the years between 2000 and 2009. The results are summarized by Figure 4, which plots the averages across time. The graph demonstrates that the specialization effect has consistently been the most important contributor to the embodied energy in international trade. However, the combination of the intensity and trade balance effects has also consistently been equally important throughout this period.

There remains scope to improve the quality of the decomposition results. The absence of an ideal indicator for the level of energy efficiency in an economy presents a challenge. Jakob and Marschinski used energy intensity based on production in their decomposition approach, while this paper considers consumption-based energy intensity to provide a superior outcome. Nevertheless, it may be possible to design a more effective decomposition approach.

Furthermore, the values of gross domestic product that were obtained from the World Input-Output Database are expressed in market exchange rates (MERs). Given that comparisons between countries were fundamental to this study, those values were converted into purchasing power parities (PPPs) using conversion factors from the World Bank. This was done because MERs measure the volume of output in a country at its price level, whereas PPPs measure the volume of output in a country at a normalized price level. By normalizing differences in price levels, PPPs offer more accurate estimates of the volume of real output (and consequently, consumption) in an economy at any particular time. However, PPPs are ultimately statistical constructs. Related uncertainties tend to grow larger when 


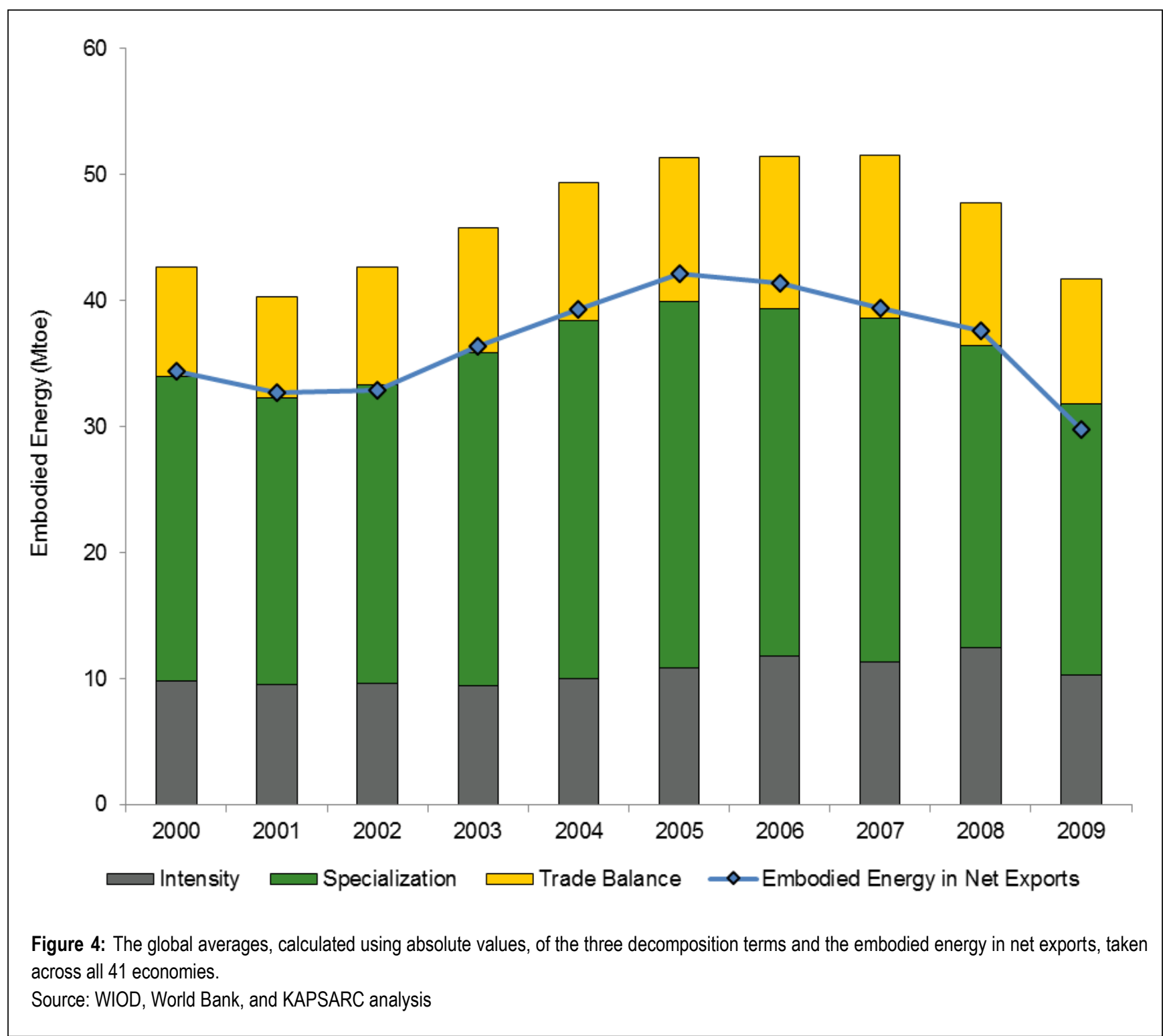

comparing dissimilar economies [11]. For example, the PPPs of China and India offer a more reliable comparison of those two countries than do the PPPs of China and the USA. The choice between PPPs and MERs has a very large impact on the decomposition results.

Other sources of uncertainty originate from the construction of input-output tables [12], and from the industry-level energy data that are used to calculate embodied energy or emissions flows [13].
Focusing on the latter, there were some discrepancies between the World Input-Output Database and the International Energy Agency's data in the total energy use of a few of the countries [14]. Some of the unexpected decomposition results, such as Denmark's specialization effect, likely stem from this. In the case of Denmark, its total energy use in the World Input-Output Database was anomalously $70 \%$ larger than the International Energy Agency value for the same year. 
Finally, we make the simplifying assumption that the three decomposition terms are independent. In reality, all three decomposition terms are interdependent, but it is expected that such higherorder effects would not significantly alter the analysis.

\section{Conclusions and implications}

Our analysis looked at 41 different economies over a time period that stretched from 2000 to 2009 . The decomposition results revealed that the specialization effect consistently made the biggest contribution to the embodied energy in international trade, although the intensity and trade balance effects were also important. While the relative importance of the three effects fluctuated from year to year, the observed trends appeared to be consistent throughout the first decade of the $21 \mathrm{st}$ century.

It is important to understand how offshoring and specialization influence each country's energy use and emissions when designing policies at a national and international level. The specialization effect offers a quantitative estimate of exactly how much more energy a specialized country would consume relative to a similar country that isn't specialized. Such insights could help policymakers better understand energy use in their countries and allow for the informed design of energy policy targets. Furthermore, they could support global discussions aimed at limiting greenhouse gas emissions.
Future work on quantifying and reducing the uncertainty in input-output calculations, and improving the energy data which are needed to compute embodied energy flows will add further value. More policy-relevant future research is needed on the "reshoring" phenomenon that may be occurring in the USA. The reshoring of manufacturing is explained as being driven by China's weakening competitive edge as its labour costs rise. Moreover, in the case of energy intensive manufacturing, reshoring has largely been instigated by the cheap natural gas that has been unlocked in the US through the shale boom. The reshoring of energy intensive industries may make it harder to achieve the goals of the policies that are designed to double US energy productivity by 2030 . However, accounting for the impact of the embodied energy in international trade, and in particular, the contributions of offshoring and specialization, can provide policymakers with insights on the consequences of such shifts in economic structure. A decomposition analysis of the US embodied energy in net exports over the next few years would deliver such insights.

\section{Acknowledgements}

I would like to thank the following researchers at KAPSARC for providing support in the early stages of this project: Berenice Garcia-Tellez, Sadeem Al-Hosain, and Christopher Napoli. 


\section{Appendix}

In this paper, decomposition analysis is used to quantify the contribution of different factors to a country's embodied energy in net exports. To conduct decomposition analysis, one needs a difference to decompose. The difference that we investigate in this paper is the difference between the embodied energy in exports and the embodied energy in imports, i.e. the embodied energy in net exports:

$$
E E N X=E E X-E E M
$$

where EENX is the embodied energy in net exports, and EEX and EEM the embodied energy in exports and imports respectively.

The first step in decomposition analysis is to take the two components of the difference and to factorize each one. We factorize each component into the three factors that can influence the embodied energy in trade: efficiency, specialization, and volume.

First, what factor can we use to measure the aggregate level of energy efficiency in an economy? Energy intensity is conventionally used. Energy intensity is defined as the ratio of energy use to gross domestic product. It measures how energy intensive total production is in an economy. By removing the effect of net exports on both the numerator and denominator of the energy intensity ratio, we introduce a measure called consumption-based energy intensity. This captures the energy intensity of consumption (production minus exports plus imports) in an economy. Unlike energy intensity, consumption-based energy intensity does not depend on the structure of an economy, thus making it a more effective measure of aggregate energy efficiency. Nevertheless, it remains a flawed measure because it is influenced by other variables.

Second, what factor can we use to measure the degree to which an economy is or isn't specialized in energy intensive exports? We define a parameter called the specialization factor to measure the degree of specialization. The specialization factor is defined as the ratio of the energy intensity of exports to consumption -based energy intensity. If the ratio is greater than one, then exports are more energy intensive than consumption, indicating a specialization in energy intensive exports. If it is less than one, then exports are less energy intensive than consumption, indicating a specialization in non-energy intensive exports.

To see how the specialization factor works, consider a country that has a moderate consumption-based energy intensity. Suppose it exports only petrochemicals - an energy intensive commodity. In this case, the country's specialization factor will be greater than one because petrochemical exports are more energy intensive than its consumption. Now suppose the country exports only agricultural goods, a non-energy intensive commodity. In this case, its specialization factor will be less than one because agricultural exports are less energy intensive than its consumption. Thus, the value of the specialization factor, whether above or below one, measures the degree to which an economy is or isn't specialized in energy intensive exports.

Third, what factor can we use to measure the volume of a country's exports? This is the most straightforward, as the monetary value of exports is a good proxy for the total volume. 
With these three factors, we can now demonstrate how to factorize the embodied energy in exports. Using the USA as an example, the embodied energy in its exports can be expressed as follows:

$$
E E X_{U S A}=E I_{U S A} \times S F_{U S A} \times X_{U S A}
$$

The first factor on the right-hand side of Equation (A2) is the consumption-based energy intensity of the USA, the second is its specialization factor, and the third is the monetary value of US exports. Note that the three factors in Equation (A2) reflect the efficiency, specialization, and volume of the USA's exports.

Analogously, we can express the embodied energy in imports for a country such as the USA as a product of three factors:

$$
E E M_{U S A}=E I_{W-U S A} \times S F_{W-U S A} \times X_{W-U S A}
$$

where the subscript "W - USA" denotes the "world minus the USA". This equation can easily be understood when one realizes that the USA's imports are exactly the same as the exports of the world minus the USA. Looking at Equation (A3) through the lens of the world minus the USA, the first factor on the right-hand side is its consumption-based energy intensity, the second is its specialization factor, and the third is the monetary value of its exports. Note how the three factors on the right-hand side simply reflect the efficiency, specialization, and volume of the world minus the USA's exports.

In summary, we can express the embodied energy in net exports as the following difference:

$$
E E X_{U S A}-E E M_{U S A}=E I_{U S A} \times S F_{U S A} \times X_{U S A}-E I_{W-U S A} \times S F_{W-U S A} \times X_{W-U S A}
$$

Using the logarithmic mean Divisia index technique for decomposition, we can convert this difference into a sum of three terms:

$$
E E X_{U S A}-E E M_{U S A}=\Delta I_{U S A}+\Delta S_{U S A}+\Delta T_{U S A}
$$

The three terms are respectively the intensity, specialization, and trade balance effects.

To understand how the decomposition technique attributes the embodied energy in net exports to the three effects, we can note that on either side of the minus sign in Equation (A4) we have a factor for the USA and a corresponding factor for the world minus the USA. For example, we have the consumption-based energy intensity of the USA on the left-hand side and its counterpart for the world minus the USA on the right-hand side. Similarly, we have the specialization factor for the USA on the left-hand side and its counterpart for the world minus the USA on the right-hand side. The decomposition technique looks at the difference between each pair. For example, if the USA's consumption-based energy intensity is higher than the world minus the USA, we have a positive difference between the pair. This produces a positive intensity effect. The positive intensity effect reflects the contribution of the USA's relative inefficiency to its embodied energy in net exports. Similarly, in the case of specialization, the decomposition technique looks at the difference between 
the specialization factor for the USA and the specialization factor for the world minus the USA. For example, if the USA has a lower specialization factor than the world minus the USA, we have a negative difference between the pair. This produces a negative intensity effect. The negative intensity effect stems from the USA's relatively more energy intensive imports. In other words, it arises from the offshoring of energy intensive activities by the US. The more a country offshores energy intensive industries, the more negative its specialization effect and the embodied energy in its net exports.

In summary, the decomposition technique looks at each pair of factors, and specifically, at the difference between each pair. A difference in each pair between a country and the world minus that country gives rise to the three decomposition terms in Equation (A5). 


\section{References}

1. Y. Kondo, Y. Moriguchi, and H. Shimizu, "CO2 Emissions in Japan: Influences of imports and exports," Applied Energy, vol. 59, pp. 163-174, 1998.

2. J. Munksgaard and K. A. Pedersen, "CO2 accounts for open economies: producer or consumer responsibility?," Energy Policy, vol. 29, pp. 327-334, 2001.

3. M. Lenzen, "Primary energy and greenhouse gases embodied in Australian final consumption: an input-output analysis," Energy Policy, vol. 26, pp. 495-506, 1998.

4. G. Machado, R. Schaeffer, and E. Worrell, "Energy and carbon embodied in the international trade of Brazil: an input-output approach," Ecological Economics, vol. 39, pp. 409-424, 2001.

5. S. J. Davis and K. Caldeira, "Consumptionbased accounting of $\mathrm{CO} 2$ emissions," Proceedings of the National Academy of Sciences, vol. 107, pp. 5687-5692, 2010.

6. G. P. Peters, J. C. Minx, C. L. Weber, and O. Edenhofer, "Growth in emission transfers via international trade from 1990 to 2008," Proceedings of the National Academy of Sciences, vol. 108, pp. 8903-8908, 2011.

7. E. E. Leamer, "The Leontief Paradox, Reconsidered," Journal of Political Economy, vol. $88,1980$.
8. M. Jakob and R. Marschinski, "Interpreting trade -related $\mathrm{CO} 2$ emission transfers," Nature Clim. Change, vol. 3, pp. 19-23, 2013.

9. M. Timmer, "The World Input-Output Database (WIOD): Contents, Sources and Methods " WIOD Working Paper Number 10, 2012.

10. G. P. Peters, "From production-based to consumption-based national emission inventories," Ecological Economics, vol. 65, pp. 13-23, 2008.

11. "Purchasing Power Parities and Real Expenditures of World Economies; Summary of Results and Findings of the 2011 International Comparison Program," World Bank, International Comparison Program, 2014.

12. C. Weber, "Uncertainties in Constructing Environmental Multiregional Input-Output Models," presented at the International InputOutput Meeting on Managing the Environment, Seville, Spain, 2008.

13. R. M. Andrew and G. P. Peters, "A MultiRegion Input-Output Table Based on the Global Trade Analysis Project Database (GTAPMRIO)," Economic Systems Research, vol. 25, pp. 99-121, 2013.

14. "Extended world energy balances," International Energy Agency, 2014. 


\section{About the author}

Anwar Gasim is a Research Associate examining the embodied energy in trade and its impact on a country's energy use and productivity. He also works on a number of projects that revolve around energy efficiency. Anwar holds a Master of Science in Electrical Engineering from the King Abdullah University of Science and Technology (KAUST) and a Bachelor of Engineering from the University of Liverpool.

\section{About the project}

The goal of this research project is to investigate how the embodied energy in trade influences energy use and productivity for each country. An understanding of each country's embodied energy trade can enable better comparisons of energy indicators between countries, allowing for a more efficient design of energy policy targets.

In line with KAPSARC's overall objectives, this research project seeks to provide insights to policymakers that can be used to inform energy and environmental policy at both a national and an international level. 